\title{
Resultado de los embarazos complicados con rubéola, 1990-1997
}

\author{
Ricardo Figueroa-Damián, M.C., M. en C., ${ }^{(1,2)}$ Federico J. 0 rtiz-Ibarra, M.C., ${ }^{(1)}$
}

José Luis A rredondo-García, M.C. ${ }^{(3)}$ José R. A hued-Ahued, M.C. . ${ }^{(4)}$

\begin{abstract}
Figueroa-Damián R, Ortiz-Ibarra FJ, Arredondo-García JL, A hued-A hued JR. Resultado de los embarazos complicados con rubéola, 1990-1997. Salud Publica Mex 1999;41:271-277.
\end{abstract}

\begin{abstract}
Resumen
Objetivo. Describir la experiencia del manejo de embarazadas con rubéola, evaluando el resultado perinatal. Material y métodos D el 1 de enero de 1990 al 31 de octubre de 1997 se incluyeron 67 embarazadas con diagnóstico de rubéola, corroborada con la determinación de anticuerpos séricos IgM. Se dio seguimiento hasta la resolución del embarazo en 66 de estas mujeres: en cuatro se realizó un aborto electivo y una tuvo un embarazo molar. En 61 pacientes se pudo evaluar el efecto de la rubéola sobre el producto y la gestación. A los productos con determinación positiva de IgM contra rubéola se les realizó ecocardio grama, estudio oftalmológico y potenciales provocados auditivos del tallo cerebral (PPATC). Resultados. El promedio de edad de las embarazadas fue de $24.7 \pm 5.5$ años; 28 pacientes cursaban su primer embarazo. N inguna de las embarazadas presentó alguna complicación del episodio de rubéola. En 35 casos (52.2\%) la infección viral se presentó durante el primer trimestre de gestación; en 23 (34.5\%) sucedió durante el segundo trimestre, y en nueve (13.3\%) ocurrió en el último trimestre. De los casos de infección materna durante el primer trimestre gestacional, $71 \%$ de los productos se infectaron y $51.6 \%$ desarrollaron un síndrome de rubéola congénita. Las manifestaciones de rubéola congénita más frecuentes fueron prematurez, bajo peso al nacimiento y alteración de los PPATC. Conclusiones. En México la rubéola continúa causando daño fetal, de tal manera que es necesario establecer medidas de prevención, como la vacunación universal, para evitar la infección por rubéola.
\end{abstract}

Palabras clave: embar azo; rubéola; síndrome de rubéola congénita; México
Figueroa-Damián R, Ortiz-Ibarra FJ, Arredondo-García JL, A hued-A hued JR. Outcome of pregnancies complicated by rubella, 1990-1997.

Salud Publica Mex 1999;41:271-277.

\begin{abstract}
A bstract
Objective To describe the experience of management of pregnant women complicated with rubella and to evaluate the perinatal outcome. Material and methods. A total of 67 pregnant women with positive IgM test for rubella were studied in the period from January $1^{\text {st }}, 1990$ to 0 ctober $31^{\text {st }}$, 1997. Sixty-six of these women were followed until the end of gestation, in 4 patients an elective abortion was performed and 1 patient had a molar pregnancy. The effects of rubella on gestation and on the product were evaluated in sixty-one of the patients. Anti-rubella IgM was determined at birth and positive infants were subjected to evaluation by echocardiogram, brainstem auditory evoked potentials (BAEP) and ophthalmological study. Results Mean age of the patients was $24.7 \pm 5.5$ years; 28 patients were primigravidae. Pregnancies were normal showing no complications due to the rubella episode. In 35 cases $(52.2 \%)$, the viral infection occurred during the first trimester of pregnancy, in 23 cases (34.5\%) during the second and in 9 (13.3\%) during the third. Seventy-one percent of infants born to mothers infected during the first trimester of pregnancy were also infected, and $51.6 \%$ develo ped congenital rubella syndrome.The most frequent manifestations of CRS were: prematurity, low birth weight and alterations of the BAEP. Conclusions In Mexico, rubella is still a cause of fetal damage, which shows the need for preventive strategies, such as universal vaccination, to avo id rubella infection during pregnancy.
\end{abstract}

Key words: pregnancy; rubella; congenital rubella syndrome; Mexico

(1) Departamento de Infectología, Instituto N acional de Perinatología (IN Per), México.

(2) Servicio de adultos. Hospital de Infectología, Centro Médico La Raza, Instituto Mexicano del Seguro Social, México.

(3) Dirección de Investigación, IN Per, México.

(4) Director General, IN Per, México.

Fecha de recibido: 4 de enero de 1999 - Fecha de aprobado: 5 de marzo de 1999.

Solicitud de sobretiros: Dr. Ricardo Figueroa. Departamento de Infectología, 40. piso, Torre de Investigación, Instituto N acional de Perinatología. Montes U rales 800, colonia Lomas de Virreyes, 11000 México, D.F., México. 
I a importancia clínica y epidemiológica de la rubéola radica en el daño que llega a ocasionar en los fetos de mujeres complicadas con esta infección viral durante la gestación. ${ }^{1}$ La afectación de los fetos es el llamado síndrome de rubéola congénita (SRC), que se presenta principalmente en los casos de infección materna durante el primer trimestre de la gestación. ${ }^{2}$

La encuesta serológica de rubéola más reciente que se ha hecho en México mostró que la prevalencia de anticuerpos contra rubéola en mujeres en edad reproductiva fue de $77 \%$ para mujeres de entre 15 y 19 años, cifra que se incrementó hasta $87.3 \%$ para el grupo de edad de 35 a 39 años; ${ }^{3}$ en algunos estados de la República, la encuesta indicó una seroprevalencia menor a $70 \%,{ }^{3}$ sobre todo entre las mujeres de zonas rurales.

A menor prevalencia de anticuerpos contra la rubéola en una población, mayor es el riesgo de que ocurra la enfermedad, llegando incluso a existir la probabilidad de un brote epidémico; tal cual sucedió en México entre 1989 y 1990, cuando hubo un total de 97367 casos. ${ }^{4}$ En consecuencia, en la medida en que aumentan los casos de rubéola, se incrementa el riesgo de que se presenten casos de SRC.

En México se ha observado un aumento en los casos de rubéola; en un estudio sobre la dinámica de transmisión de esta enfermedad en México se encontró que, de 1983 a 1990, hubo un incremento considerable de rubéola en el grupo de 15 a 44 años de edad, ${ }^{5}$ por lo que es probable que también haya aumentado la ocurrencia de rubéola en mujeres embarazadas.

El objetivo de este artículo es describir la experiencia del Instituto Nacional de Perinatología (INPer) en el manejo de pacientes complicadas con rubéola durante su embarazo, evaluando el resultado perinatal, la frecuencia de infección congénita y las manifestaciones más comunes de los recién nacidos afectados por el SRC.

\section{Material y métodos}

Entre el 1 de abril de 1990 y el 31 de octubre de 1997 se estudiaron 67 pacientes embarazadas a quienes se les diagnosticó rubéola clínica y serológicamente. Todas fueron atendidas en el Departamento de Infectología del INPer. Se elaboró una historia clínica completa de cada una de las embarazadas con sospecha clínica de padecerla, y el diagnóstico se corroboró mediante la determinación sérica de IgM contra rubéola. A aquellas pacientes que tenían diagnóstico de rubéola y que se encontraban en el primer trimestre de la gestación, mismo que se calculó a partir de la fecha de la última menstruación, se les realizó ultrasonido (US) obstétrico para identificar alteraciones fetales compa- tibles con daño ocasionado por rubéola. Cabe señalar que, a partir de 1994, en estos casos también se efectuó cordocentesis para determinación de IgM contra rubéola en sangre fetal. Con los resultados de estos estudios, el comité de evaluación de embarazos de alto riesgo del INPer revisó los casos de las pacientes que cursaban con menos de 20 semanas de gestación (SDG) y recomendó, para cada caso, continuar o interrumpir la gestación. Para someter un caso a dicho comité, previamente se solicitó autorización a los padres.

Aquellas pacientes que siguieron adelante con el embarazo quedaron incluidas en una cohorte de estudio, sometidas a una evaluación clínica periódica así como al seguimiento del crecimiento y desarrollo del feto mediante estudios de US obstétrico. Se hizo el seguimiento hasta la resolución del embarazo en $66 \mathrm{ma}$ dres; en cuatro de ellas se realizó un aborto electivo y una paciente tuvo un embarazo molar. En 61 pacientes se pudo sopesar el efecto de la enfermedad sobre el producto y la gestación.

Se evaluó clínicamente a los neonatos en el nacimiento, y se tomó una muestra de sangre de cordón para la determinación de IgM contra rubéola. En los niños con resultado negativo se repitió el estudio entre los dos y tres meses de vida. Los niños con determinación positiva de IgM contra rubéola en cualquiera de las mediciones se consideraron como portadores de infección congénita y se sometieron a estudio, el cual consistió en la valoración oftalmológica, la valoración cardiológica, ecocardiograma y la evaluación auditiva a partir de la medición de PPATC. Todos los recién nacidos con infección congénita quedaron incluidos en un programa de seguimiento. Se consideró como sanos a los niños con determinaciones negativas de IgM y se les dio de alta.

Con la totalidad de casos se realizó un estudio de cohorte retrospectivo en el cual se revisó la evolución obstétrica, la frecuencia de infección congénita, el porcentaje de niños con anormalidades congénitas secundarias a la rubéola materna y el tipo de alteraciones que se encontraron en esos recién nacidos.

Se utilizó estadística descriptiva con determinación de frecuencias, proporciones y cálculo de medidas de tendencia central y dispersión.

\section{Resultados}

El promedio de edad de las embarazadas complicadas con rubéola fue de $24.7 \pm 5.5$ años, con una mediana de 25 y un intervalo de 16 a 36 años. De las mujeres estudiadas, $28(41.8 \%)$ presentaron la infección en su primer embarazo, 18 (26.9\%) durante su segunda gestación, 13 (19.4\%) cursaban el tercer embarazo y en ocho 
(11.9\%) el cuadro de rubéola ocurrió en la cuarta o en las subsiguientes gestaciones. Sólo $11(16.4 \%)$ pacientes identificaron el contacto de rubéola; en nueve de ellas éste correspondió a familiares que habitaban el mismo domicilio y en dos los contactos fueron personas ajenas al ámbito familiar.

La rubéola ocurrió durante el primer trimestre de la gestación en 35 (52.2\%) casos, en el segundo en 23 $(34.5 \%)$ y durante el tercer trimestre en nueve (13.5\%). Ninguna de las mujeres embarazadas presentó complicaciones del episodio de rubéola; las manifestaciones clínicas cedieron en un lapso de 7 a 10 días; todas se manejaron exclusivamente con tratamiento sintomático. De estas pacientes, 39 (58.2\%) tuvieron un curso normal de su embarazo después de la complicación infecciosa, mientras que $28(41.8 \%)$ presentaron alguna complicación médica u obstétrica. En el cuadro I se indican las complicaciones del embarazo posiblemente relacionadas con el episodio de rubéola, de acuerdo con el momento de la gestación en que se presentó la infección. En el cuadro II se muestra la evolución de la totalidad de los productos, según las se-

\section{Cuadro I}

\section{Complicaciones del embarazo posiblemente} RELACIONADAS CON LA RUBÉOLA SEGÚN EL MOMENTO EN QUE OCURRIÓ LA INFECCIÓN MATERNA. INSTITUTO Nacional de Perinatología, México, 1990-1997

\begin{tabular}{|c|c|c|c|c|}
\hline $\begin{array}{l}\text { Edad gestacional } \\
\text { al momento de la } \\
\text { rubéola (semanas) }\end{array}$ & No. & Complicaciones & No. & $\%$ \\
\hline 1 a 3 & 3 & O ligohidramnios, RCIU & 1 & 33.3 \\
\hline \multirow[t]{3}{*}{4 a 6} & 5 & O ligohidramnios, RCIU & 1 & 20 \\
\hline & & Parto pretérmino, RCIU & 1 & 20 \\
\hline & & Aborto terapéutico & 2 & 20 \\
\hline \multirow[t]{3}{*}{7 a 9} & 15 & Muerte fetal & 1 & 6.6 \\
\hline & & Aborto terapéutico & 1 & 6.6 \\
\hline & & Parto pretérmino, RCIU, RPM & 1 & 6.6 \\
\hline \multirow[t]{5}{*}{10 a 12} & 12 & Amenaza de aborto & 1 & 8.3 \\
\hline & & Aborto espontáneo & 1 & 8.3 \\
\hline & & RCIU & 1 & 8.3 \\
\hline & & 0 ligohidramnios, RCIU, parto & & \\
\hline & & pretérmino & 1 & 8.3 \\
\hline \multirow[t]{2}{*}{13 a 15} & 8 & Aborto terapéutico & 1 & 12.5 \\
\hline & & Aborto espontáneo & 2 & 25 \\
\hline 16 a 18 & 7 & Amenaza de parto pretérmino & 1 & 14.2 \\
\hline 19 a 21 & 5 & RPM & 1 & 20 \\
\hline 22 a 24 & 3 & - & - & - \\
\hline 25 a 27 & 4 & Parto pretérmino & 1 & 25 \\
\hline$>28$ & 5 & - & - & \\
\hline
\end{tabular}

RCIU: retardo en el crecimiento intrauterino RPM: ruptura prematura de membranas

\section{Cuadro II \\ EvoluCión de LOS PROdUCTOS DE ACUERDO CON LA EDAD GESTACIONAL AL MOMENTO DE LA INFECCIÓN MATERna. INSTITUTO NaCional de Perinatología, México, 1990-1997}

Edad

gestacional

(semanas) No. Síntomas de rubéola congénita

\begin{tabular}{|c|c|c|}
\hline 1 a 3 & 3 & 1: bajo peso al nacer, PPATC anormales \\
\hline & & 1: 0 ligohidramnios con bajo peso al nacer y PCA \\
\hline & & 1: lgM +, asintomático \\
\hline 4 a 6 & 5 & 2: Prematuros ( 33 y 35 sdg) con bajo peso al nacer \\
\hline & & 2:Abortos terapéuticos \\
\hline & & 1: 0 ligohidramnios, bajo peso al nacer, PCA \\
\hline & & hepato megalia, trombocitopenia, cataratas \\
\hline 7 a 9 & 15 & 3: IgM +, asintomático \\
\hline & & 1: Muerte fetal \\
\hline & & 1: Bajo peso al nacer con CIA \\
\hline & & 1:PPATC anormales \\
\hline & & 1: Ictericia \\
\hline & & 1: O ligohidramnios \\
\hline & & 1:Aborto terapéutico \\
\hline & & 6: IgM -, no infectados \\
\hline 10 a 12 & 12 & 2: PPATC anormales \\
\hline & & 2: lgM +, asintomáticos \\
\hline & & 1:Aborto espontáneo \\
\hline & & 1: Embarazo molar \\
\hline & & 1: Bajo peso al nacer, con PPATC anormales \\
\hline & & 1:PPATC anormales y retinopatía \\
\hline & & 1: Prematuro (35 sdg), PCA, PPATC anormales \\
\hline & & y exantema \\
\hline & & 3: IgM -, no infectados \\
\hline 13 a 15 & 8 & 2:Abortos espontáneos \\
\hline & & 1:PPATC anormales \\
\hline & & 1:Aborto terapéutico \\
\hline & & 1: lgM +, asintomático \\
\hline & & 3: IgM -, no infectados \\
\hline 16 a 18 & 7 & 1: IgM +, asintomático \\
\hline & & 1:A bandonó el Instituto \\
\hline & & 5: IgM -, no infectados \\
\hline 19 a 21 & 5 & 1: Ictericia \\
\hline & & 4: IgM -, no infectados \\
\hline 22 a 24 & 3 & 1: IgM +, asinto mático \\
\hline & & $2: \lg M-$, no infectados \\
\hline 25 a 27 & 4 & $4: \lg M-$, no infectados \\
\hline 28 a 30 & 1 & 1: IgM -, no infectados \\
\hline$>30$ & 4 & 2: IgM +, asintomático \\
\hline & & 1: Muerte fetal (prolapso de cordón) \\
\hline & & 1: IgM -, no infectado \\
\hline
\end{tabular}

PPATC: potenciales provocados auditivos del tallo cerebral Sdg: semanas de gestación

PCA: persistencia del conducto arterioso

CIA: comunicación interauricular 
manas de gestación al momento de la rubéola materna. Todos los productos que presentaron alguna alteración clínica o anormalidad en los estudios de gabinete tuvieron una determinación positiva de la IgM contra rubéola, en tanto que, de los niños no infectados (IgM contra rubéola negativa), ninguno presentó alteraciones.

De los 35 casos de rubéola en el primer trimestre de gestación, 31 productos llegaron a una edad gestacional de viabilidad; de éstos, $22(70.9 \%)$ se determinaron como infectados al nacimiento y $16(51.6 \%)$ presentaron alguna manifestación clínica de la infección, por lo que se consideraron portadores de SRC (cuadro III). Cuatro productos no fueron evaluables, en tres casos porque se realizó una aborto terapéutico y en el cuarto porque correspondió a un embarazo molar. De los 23 casos en los que la infección ocurrió durante el segundo trimestre de la gestación, 21 productos fueron evaluables, siete $(33.3 \%)$ de los cuales se encontraron infectados, y cuatro $(19 \%)$ tuvieron manifestaciones de rubéola congénita (cuadro III). Los dos productos no evaluables correspondieron, uno, a un aborto terapéutico, y el otro, a un caso en el cual la embarazada abandonó la atención en el INPer. De los nueve casos ocurridos en el último trimestre del embarazo, ocho productos fueron evaluables: hubo dos $(25 \%)$ infectados, pero sin que ninguno de ellos presentara alguna alteración compatible con SRC. El caso no evaluable correspondió a un óbito cuya causa no se

\section{Cuadro III \\ Frecuencia de rubéola congénita de acuerdo CON LA EDAD GESTACIONAL AL MOMENTO DE LA INFECCION MATERNA. INSTITUTO NaCIONAL DE Perinatología, México, 1990-1997}

\begin{tabular}{lrccc}
$\begin{array}{l}\text { SDG al momento } \\
\text { de la rubéola }\end{array}$ & N & $\begin{array}{c}\text { Neonatos } \\
\text { Evaluados }\end{array}$ & $\begin{array}{c}\text { No. Infectados } \\
(\%)\end{array}$ & $\begin{array}{c}\text { No. Dañados } \\
\text { (SRC) (\%) }\end{array}$ \\
1 a 12 & 35 & 31 & $22(70.9)$ & $16(51.6)$ \\
\hline 13 a 24 & 23 & 21 & $7(33)$ & $4(19)$ \\
\hline 25 a 38 & 9 & 8 & $2(25)$ & 0
\end{tabular}

SD G : semanas de gestación.

SRC: síndrome de rubéola congénita

relacionaba con la rubéola, pues se trató de una insuficiencia aguda de la circulación feto-placentaria.

En la serie de pacientes las manifestaciones más frecuentes de rubéola congénita fueron: recién nacidos hipotróficos, alteración en los PPATC, cardiopatía y recién nacidos prematuros. Los neonatos prematuros nacieron entre las 33 y la 35 SDG. No hubo casos de niños con microcefalia. Hubo una muerte, a los 17 días de vida extrauterina, atribuible al SRC. En el cuadro IV se presentan las manifestaciones de la rubéola congénita encontradas, de acuerdo con el trimestre de gestación en que ocurrió la infección materna.

Cuadro IV

MANIFESTACIONES DE RUBÉOLA CONGÉNITA, SEGÚN EL TRIMESTRE DE GESTACIÓN, DE LA INFECCIÓN MATERNA. Instituto Nacional de Perinatología, México, 1990-1997

\begin{tabular}{|c|c|c|c|c|c|c|c|}
\hline 1er. trimestre, $n=31$ & No. & $\%$ & 20. trimestre, $n=21$ & No. & $\%$ & 3er. trimestre, $n=8$ & No. \\
\hline PPATC anormales & 7 & 22.5 & Abortos espontáneos & 2 & 9.5 & No afectados & 8 \\
\hline Bajo peso al nacer & 7 & 22.5 & PPATC anormales & 1 & 4.7 & & \\
\hline Malformaciones cardiacas & 4 & 12.9 & Ictericia & 1 & 4.7 & & \\
\hline PCA & 3 & 9.6 & & & & & \\
\hline $\mathrm{CIA}$ & 1 & 3.2 & & & & & \\
\hline Prematurez & 3 & 9.6 & & & & & \\
\hline Cataratas & 1 & 3.2 & & & & & \\
\hline Retinopatía & 1 & 3.2 & & & & & \\
\hline Ictericia & 1 & 3.2 & & & & & \\
\hline Hepatomegalia & 1 & 3.2 & & & & & \\
\hline Exantema & 1 & 3.2 & & & & & \\
\hline Trombocitopenia & 1 & 3.2 & & & & & \\
\hline Muerte fetal & 1 & 3.2 & & & & & \\
\hline Aborto espontáneo & 1 & 3.2 & & & & & \\
\hline \multicolumn{8}{|c|}{$\begin{array}{l}\text { PPATC : potenciales provocados auditivos del tallo cerebral } \\
\text { PCA: persistencia del conducto arterioso } \\
\text { CIA: comunicación interauricular }\end{array}$} \\
\hline
\end{tabular}




\section{Discusión}

La infección por el virus de la rubéola constituye un problema de salud pública mundial: cuando ocurre durante la infancia, su curso suele ser benigno; sin embargo, si se presenta durante el embarazo, sobre todo en el primer trimestre, existe un riesgo importante de afectación al producto. ${ }^{6}$ No obstante la reducción en el número de casos del SRC en los países industrializados, en las naciones en desarrollo persiste la problemática; en este estudio se demuestra que la rubéola congénita continúa siendo un problema de salud en México.

Gregg hizo la primera descripción de la afectación fetal $^{7}$ a principios de la década de 1940, al informar acerca de 78 lactantes con catarata congénita; 67 de las madres habían cursado con rubéola al inicio del embarazo. No obstante, fue sólo hasta que ocurrió la pandemia de rubéola al inicio de los años sesenta cuando se reconoció claramente la importancia de la infección viral como causa de daño fetal. Como resultado de un brote ocurrido en 1964 en la ciudad de Nueva York, más de 1000 niños nacieron con el SRC y cerca de 300 mujeres infectadas abortaron espontáneamente. ${ }^{8}$ En esa misma década, Sever y colaboradores ${ }^{9}$ estudiaron 6000 embarazadas de Estados Unidos de América (EUA) complicadas con rubéola, y encontraron que $10 \%$ de ellas tuvieron hijos con SRC.

En los países no industrializados se desconoce la prevalencia real de la infección debido a que no se notifican muchos de los casos. ${ }^{10}$ Los estudios de seroprevalencia se aproximan a conocer ese parámetro, y en algunos se ha informado de una prevalencia menor de anticuerpos contra rubéola en mujeres de entre 15 y 30 años en países como Brasil con $82 \%$, mientras que en Chile, Nigeria, Sudáfrica y Jamaica la seroprevalencia descrita oscila entre 92 y $100 \% .{ }^{10}$ En México se ha informado que en mujeres de entre 15 y 40 años de edad existe una prevalencia de anticuerpos contra rubéola cercana a $85 \%{ }^{3}$

La incidencia de rubéola en el embarazo depende del número de mujeres embarazadas que son susceptibles a la infección viral, mientras que el riesgo de daño fetal depende de la edad gestacional en la cual ocurre la infección materna. ${ }^{11}$ La probabilidad de infección fetal es diferente a la de afectación; la primera es más frecuente y puede presentarse en cualquier etapa del embarazo, mientras que la afectación ocurre principalmente en los casos de rubéola materna en el primer trimestre del embarazo. La infección corresponde a la presencia de anticuerpos IgM contra rubéola en sangre del recién nacido, mientras que la afectación in- dica la presencia de alguna anormalidad congénita producida por la infección.

En este estudio, $71 \%$ de los productos de los casos de rubéola materna ocurrida durante el primer trimestre se infectaron, pero al nacimiento sólo hubo evidencia de afectación en $51.6 \%$ de los neonatos. En el estudio de Miller y colaboradores, ${ }^{12}$ la infección materna que ocurrió antes de la semana 11 de gestación ocasionó infección en $90 \%$ de los productos y afectación también en 90\% de los mismos; la rubéola que se presentó entre las semanas 11 y 12 de gestación condujo a la infección de $67 \%$ de los productos y a la afectación de sólo 33\%.

En este trabajo se observó que los niños cuya madre presentó la infección en etapas más tempranas del embarazo tuvieron una frecuencia mayor de afectación: $51.6 \%$ de los niños cuyas madres presentaron rubéola durante el primer trimestre de la gestación nacieron con el SRC. El porcentaje de afectación se redujo a 19\% entre los niños con infección materna durante el segundo trimestre gestacional, y de los casos de rubéola materna en el tercer trimestre gestacional ninguno de los recién nacidos presentó manifestaciones de rubéola congénita. En un informe previo, Sánchez y Torres ${ }^{13}$ indicaron la existencia en México de 16 mujeres embarazadas con rubéola, dentro de las primeras 16 SDG; a 12 productos se les determinó IgM contra rubéola al nacimiento, y todos fueron positivos; de siete niños con rubéola materna en el primer trimestre de gestación, sólo dos $(28.5 \%)$ nacieron con manifestaciones del SRC.

En los primeros estudios retrospectivos sobre las consecuencias de la rubéola en el embarazo, se estimó un riesgo de defectos congénitos hasta de $90 \%$ en los casos de infección materna durante el primer trimestre. ${ }^{14}$ Los trabajos posteriores, llevados a cabo de manera prospectiva, han mostrado una variación importante en los resultados, habiéndose informado acerca de una incidencia de defectos congénitos de 10 a $54 \%$, para los casos de rubéola del primer trimestre de gestación. ${ }^{15,16}$ En esos mismos estudios se ha mostrado que la mayoría de los productos infectados después de las 20 SDG no presenta anormalidades congénitas evidentes al nacimiento, por lo que debe establecerse un programa de seguimiento para identificar las anormalidades que se hagan aparentes con el desarrollo del niño. La proporción de embarazos interrumpidos electivamente, cuatro $(6 \%)$ en la serie de este estudio, modifica las tasas de incidencia que se han descrito acerca de niños con daño congénito.

Cabe destacar que la importante reducción que se aprecia en este estudio de la afectación fetal en aquellos casos en los que la madre se infectó, después de 
las 15 SDG ya no se observó el SRC en ninguno de los productos y además disminuyó el número de niños infectados. Este hallazgo coincide con los de estudios previos en los que se describió que sólo $10 \%$ de los niños de madres con rubéola en el cuarto mes de la gestación presentaron un defecto congénito y que únicamente de manera ocasional existió daño fetal en los casos de rubéola materna después de las 20 SDG. ${ }^{17}$

En los niños identificados con SRC, las alteraciones más frecuentes encontradas al nacimiento fueron: hipotrofia, PPATC anormales, cardiopatía y prematurez. En la serie de este estudio no se identificaron niños con microcefalia. Los resultados concuerdan con los de estudios previamente publicados; Horstmann y colaboradore ${ }^{18}$ describieron el retardo en el crecimiento intrauterino (RCIU) como la manifestación más común de rubéola congénita. Por otra parte, hubo dos hallazgos frecuentes en sus pacientes, que no se observaron en esta serie, y que fueron hepatoesplenomegalia y catarata. Cooper ${ }^{19}$ informó que más de $50 \%$ de los niños con rubéola congénita tuvieron defectos auditivos, y entre 20 y $50 \%$ presentaron algún tipo de retinopatía; no obstante, también describió hallazgos diferentes a los del presente estudio, como adenomegalias y radiolucencia ósea hasta en 50\% de los recién nacidos.

Es importante señalar que en el SRC, además de los defectos congénitos permanentes como cardiopatía, alteraciones de la retina o defectos auditivos, existen manifestaciones que pueden variar con el tiempo, como la hepatoesplenomegalia, la trombocitopenia o la ictericia, que están presentes al nacimiento pero que desaparecen después de varias semanas de vida. Por otra parte también ocurren manifestaciones ausentes al nacimiento pero que se hacen evidentes con el desarrollo y crecimiento de los niños infectados, como son los casos de retraso psicomotor, alteraciones psiquiátricas y anormalidades endócrinas. ${ }^{2}$

El presente estudio representa la serie más grande de casos de rubéola congénita informada en México, y pone de manifiesto que la rubéola durante el embarazo es, actualmente, un problema de salud pública. En su carácter de hospital de referencia, el INPer aglutina un número importante de embarazos complicados, por lo que la frecuencia de embarazadas con rubéola es superior a lo observado en hospitales generales; no obstante, para centros hospitalarios de referencia es probable que la frecuencia de esta complicación infecciosa sea semejante. Por otro lado, se considera factible transpolar estos resultados a la población mexicana en general, tomando en cuenta que las pacientes atendidas no tuvieron características demográficas especiales.
En consideración a la severidad de las repercusiones del SRC es necesario establecer medidas preventivas contra la rubéola; la que se ha identificado como la más importante es la prevención de la infección materna. Entre las intervenciones preventivas destacan la vacunación universal, el escrutinio pregestacional de anticuerpos contra rubéola con vacunación de las mujeres seronegativas, y la vacunación a mujeres durante la adolescencia.

Se ha demostrado con claridad que la rubéola es prevenible mediante vacunación. ${ }^{20}$ La vacuna contra rubéola se encuentra disponible desde hace más de dos décadas y ha mostrado ser, tanto en EUA como en Inglaterra, altamente efectiva; cerca de $95 \%$ de los individuos inmunizados desarrollan anticuerpos séricos detectables, que persisten cuando menos durante 10 años. ${ }^{21}$

\section{Referencias}

1. Lindegren ML, Fehrs L, H adler S, Hinman A. U pdate: Rubella and congenital rubella syndrome, 1980-1990. Epidemiol Rev 1991;13:341-348.

2. Cooper L, Preblud S, Alford Jr C. Rubella. En: Remington J, Klein J, ed. Infectious diseases of the fetus and newborn infant. 4a. edición. Filadelfia: W B Saunders, 1995:268-311.

3. Gutiérrez G, Muñoz O,Tapia R, Bustamante ME,Alvarez MT, Guiscafré $J P$ et al. Seroepidemiología de la rubéola en mujeres mexicanas. Encuesta N acional Probabilística. Salud Publica Mex 1990;32:623-631.

4. Información epidemiológica de morbilidad. Estados Unidos Mexicanos, 1989 y 1990. México, D.F.: Secretaría de Salud-Dirección General de Epidemiología, 1990

5. José MV, O Ivera J, Serrano 0. Epidemiología de la rubéola en México. Salud Publica Mex 1992;34:318-327.

6.Tapia-C onyer R, Sepúlveda J, Salvatierra B, Muñoz O, Bustamante-C alviIlo $\mathrm{ME}$,Alvarez $\mathrm{T}$ et al. Factores determinantes de la rubéola en población de 10 a 14 años de edad en México. Salud Publica Mex 1992;34:211-221. 7. Gregg N M. Congenital cataract following German measles in the mother. Trans 0 phthalmol Soc A ust 1941;3:35-46.

8. Cooper LZ.The history and medical consequences of rubella. Rev Infect $D$ is 1985; 7 suppl:2-10.

9. Sever JL, Karin BN, Gilkenson MR. Rubella epidemic 1964: Effect on 6000 pregnancies. Am J Dis Child 1965;110:310-314.

10. Miller CL. Rubella in the developing world. Epidemiol Infect 1991;107: 63-68.

11.AC O G Technical Bulletin. Rubella and pregnancy. Int J Gynecol 0 bstet 1993:42:60-66.

12. Miller E, Cradock-W atson JE, PollockTH. C onsequences of confirmed maternal rubella at successive stages of pregnancy. Lancet 1982;2: 781-784.

13. Sánchez E, Torres R. Rubéola y embarazo. Resultados perinatales. Ginecol O bstet Mex 1992;60:141-145.

14. Peckham C. Congenital rubella in the United Kingdom before 1970: The prevaccine era. Rev Infect D is 1985; 7 suppl:11-14.

15. Lundstrom R. Rubella during pregnancy.A follow-up study of children born after an epidemic of rubella in Sweden. Acta Pediatr 1962;51 suppl 133:1-6.

16. Sallomi SJ. Rubella in pregnancy.A review of prospective studies from the literature. 0 bstet Gynecol 1966;27:252-255. 
17. Marshall W C. Rubella: C urrent problems and recent development. $\mathrm{Br}$ J Clin Pract 1976;30:56-59.

18. H orstmann DJ,Banatvala LE, Riordan JT. Maternal rubella and the rubella syndrome in infants. Am J D is Child 1965;110:408-412.

19. Cooper LZ.A preventable cause of birth defects. En: Bergsman D, ed. Birth defects. Nueva York: N ational Foundation-March of Dimes, $1968 ; \mathrm{vol} 4$.
20. Centers for Disease Control, Immunization Practices Advisory Committee. Increase in rubella and congenital rubella syndrome-U nited States, 1988-1990. MMW R Morb Mortal W kly Rep 1991; 40:93-99.

21. Sever JL, Larsen J, G rossman J. Handbook of perinatal infections. 2a. edición. Boston: Little Brown, 1989. 